\title{
Autoradiographical Study of the Nucleolus in Neurons of the Reticular Formation of the Avian Brain
}

\author{
Tomas P. Pessacq \\ Cátedra de Histologia, Fac. de Cs. Exactas, Casilla de Correo No. 540, \\ (1900) La Plata, Argentina
}

Received September 30, 1978

\section{Introduction}

Some works suggest that the incorporation of labelled precursors of RNA begins in several cellular types in the nucleolus and its associated chromatin (Perry and Errera 1960, Hiatt 1962, Mitchison 1966, Izawa and Kawashima 1968, Satake et al. 1968, Soeiro 1968, Liau et al. and Perry 1969). With the aim to verify if similar results are obtained in avian neurons, we have undertaken the present study.

\section{Material and methods}

Newly hatched chickens were injected intracranially with $20 \mu \mathrm{Ci}$ of $\left[{ }^{3} \mathrm{H}\right]$ uridine (sp. act. 12 to $13 \mathrm{Ci} \mathrm{m}$ mole) dissolved in $0.1 \mathrm{ml}$ of physiological salt solution. The chicks were inoculated through the anterior fontanelle using a $1 / 2$ in. long needle. Post mortem examination of animals showed that in most cases the injection had fallen in the cerebellar cisterne. At 1/4, 1, 4, 16 and 24 hour intervals the animals were sacrificed by decapitation.

\section{Resuits and discussion}

In previous works we have studied some structural aspects of the neuronal nucleolus and its associated chromatin. It was shown that in avian neurons the nucleolus is connected to a varying in shape chromatinic mass (Pessacq 1969). The structural arrangement of the nucleolar chromatinic complex, seems to depend on the neuronal type, the age of the animal and several functional conditions (Pessacq 1973, 1974, 1975, unpublished data). The present observations were mainly recalled in the labelling patterns of the nucleolus of neurons of the reticular formation of the brain stem. In these cells the nucleolar chromatinic complex shows two different structural arrangements: I) a single chromatinic mass adherent to the nucleolus and II) two chromatinic bodies applied side by side to a central nucleolar zone. Both nucleolar types are illustrated in Figs. 1 and 2. In the animals sacrificed 15 minutes to 2 hours after the injection, the labelling appears in both nucleolar types densely packed over the nucleolar chromatinic mass (Figs. $1 \mathrm{~b}$ and $2 \mathrm{a}$ ). In the animals sacrificed 3 to 12 hours after the injection the labelling appears more diffusely spread over the nuclear sap (Figs. 1a and 

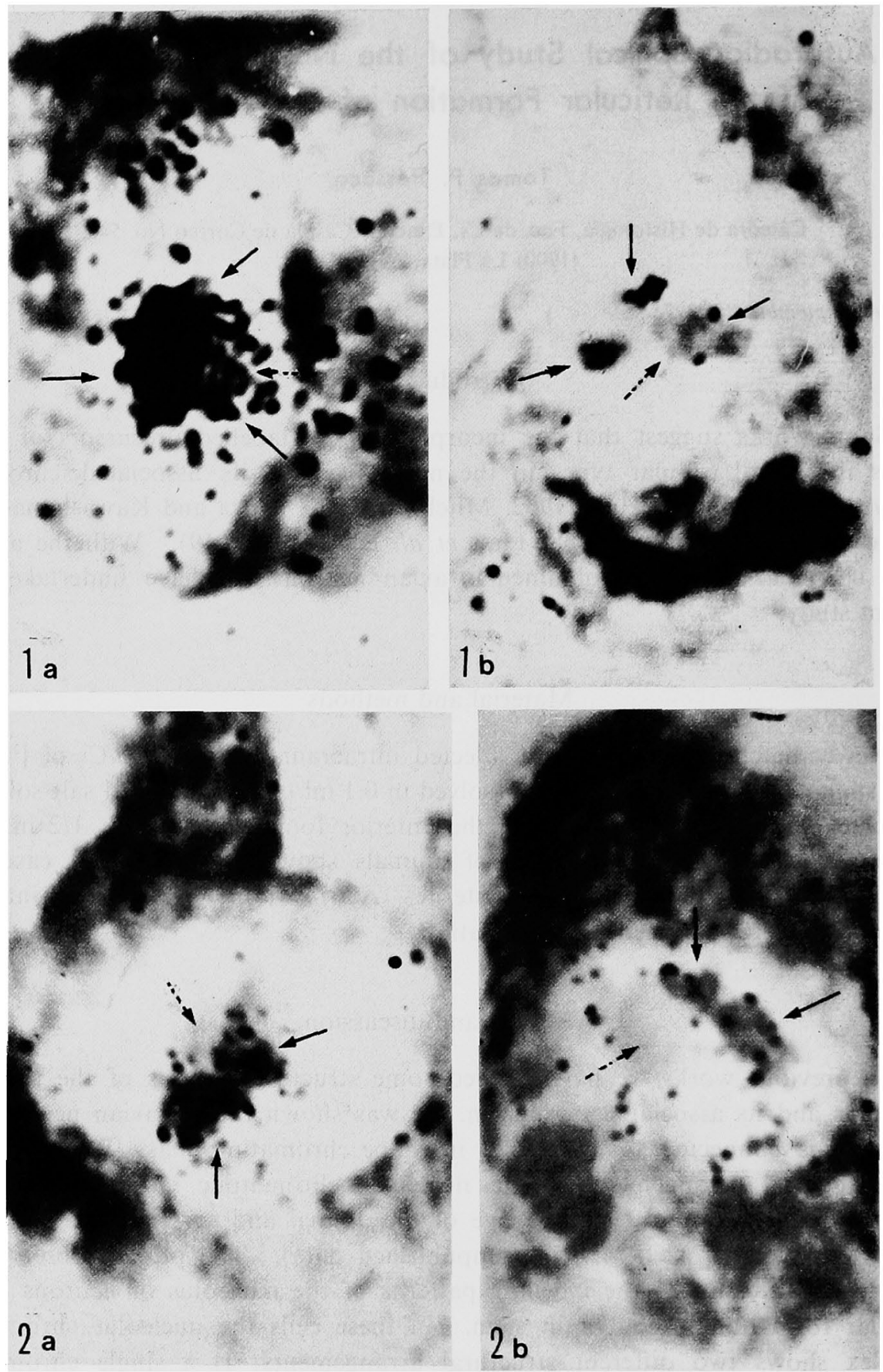

Figs. 1-2. 1a-b, single nucleolar chromatinic body (arrow) and $b$ : double nucleolar chromatinic body (arrows) heavily labeled in neurons of the reticular formation. a, the labeling is partially spread over the whole nucleus. The dotted arrows point out the nucleolar mass. The picture a corresponds to an animal sacrificed 4 hours after the injection. b, another sacrificed 15 , minutes after the injection. 2a-b. Double nucleolar chromatinic bodies heavily stained. a, showing correspond to an animal sacrificed 15 minutes after the injection. b, another sacrificed 4 hours after the injection. In both cases the chromatinic bodies are partially fused. The dotted arrows indicate the nucleolar zone. 
2b). This result would indicate that the neuronal nucleolar chromatinic complex incorporates previously than other nuclear regions the labeled precursors of the RNA. According to the observations of other authors "the RNA labeled in the nucleolar region consists of 38 and $45 \mathrm{~S}$ molecules, the nucleotides of which ultimately become part of the 18 and 28 S ribosomal RNA" (Perry et al. 1964). The facts reported here would permit to extend to nerve cells the postulations of those authors which maintain that the nucleolus and its associated chromatin exert a sort of controling action over the RNA synthetic activities of other parts of the cell (Mitchison 1966).

\section{Summary}

The incorporation of tritiated uridine into the nucleolus and its associated chromatin of avian neurons is studied. The nucleolar chromatinic complex of this cellular type seems to incorporate the labeled precursors of the RNA previously than other cellular parts.

\section{References}

Hiatt, H. 1962. A rapidly labeled RNA in rat liver nuclei. J. mol. Biol. 5:217.

Izawa, M. and Kawashima, K. 1968. RNA synthesis in the nucleoli of mouse ascites tumor cells in relation to nucleolar components. Biochim. Biophys. Acta. 155: 51.

Liau, M. C. and Perry, R. P. 1969. Ribosome precursor particles in nucleoli. J. Cell Biol. 42: $272-283$.

Mitchison, J. M. 1966. Some functions of the nucleus. International Review of Cytology. Edited by G. H. Bourne and J. F. Danielli. 19: 97-110, Academic Press.

Perry, R.P and Errera, M.1960. The influence of nucleolar ribonucleic acid metabolism on that of the nucleus and cytoplasm. In The Cell Nucleus (Mitchel, J. S., ed) London, Butterworth and Co., p. 24.

-, Srinivasan, P. R. and Kelley, D. E. 1964. Hybridization of rapidly labeled unclear ribonucleic acids. Science 145: 504-507.

Perry, R. P. 1071, (Personal Communication).

Pessacq, T. P. 1969. Cyclic changes in the structure of nucleolus-associated chromatin in neurons of birds. Cytologia 34: $375-381$.

- 1973. Unpublished observations.

- 1974. Ibid.

- 1975. Ibid.

Satake, M., Matsukawa, S., Miyazawa, N. 1968. Rapidly labelled RNA in the hibernating bat brain. Jourmed 218 : 768-769.

Soeiro, R., Vaughan, M. H. and Darnell, J. E. 1968. The effect of Puromycin on intranuclear steps in ribosome biosynthesis. Cell Biol. 36: 99-101.

- 1971 (Personal Communication). 